\title{
Paper \\ Effect of Projection Size of Partition Frame on Separation of Two Recognized Visual Spaces of Illumination
}

\author{
Yoko MIZOKAMI, Mitsuo IKEDA and Hiroyuki SHINODA \\ Ritsumeikan University
}

Paper ordinally published in Japanese in J.IEIJ, Vol.83-No.5, 1999

\begin{abstract}
The size of the recognized visual space of illumination (RVSI) is a concept for expressing the perception of brightness of a space recognized by an observer. If he/she recognizes the space as being brightly illuminated, the size of RVSI is said to be large. The apparent lightness of an object placed in the space is determined relative to the size of the RVSI. The size is controlled by changing the illumination level of the space. It can also be controlled by changing the lightness of the interior of the space even if the illumination is kept constant. Then the apparent lightness of the object becomes lower with an interior having high lightness. Two miniature rooms in the depth direction from a subject, were illuminated at the same illuminance level, but the front room had walls, floors and fumiture with lower lightness than the back room. It was expected that the RVSI of the front room would be smaller in size than that of the back room. The two rooms were separated by a partition frame projecting from the side walls. In this paper the effect of the projection size of the partition on the size change of RVSI at the boundary of the two rooms was investigated by measuring the apparent lightness of a test patch along the depth of the rooms for three different projection sizes. It was found that the effect of projection size was not significant and that the separation into two RVSIs was mainly achieved by interior lightness.
\end{abstract}

KEYWORDS: lightness, apparent lightness, brightness, illumination, recognized visual space of illumination

\section{Introduction}

It is important for lighting design to know how human beings perceive illuminated space and, for this purpose, Ikeda et al. have introduced the concept of the recognized visual space of illumination, RVSI') 2). The RVSI can be briefly summarized as the recognition of the illumination status of a space when it is seen by a person, and it has characteristics such as brightness, color, and stability. The level of brightness at the level of recognition is expressed by the word "size", and it is said that the size of the RVSI is large when it is felt that a space is brightly illuminated, while it is said to be small when it is felt to be darkly illuminated. Factors determining the size of the RVSI are the appearance of the things that is seen first by a person, such as the objects in the space, the luminaire that illuminates the space and the windows through which the light comes from outside, and they are called the initial visual information. Therefore, the size of the RVSI can be changed by changing the initial visual information.

The above was shown by Ikeda et al. ${ }^{3)}$, who made two miniature rooms consisting of a room with walls and furniture with high lightness and another room with low lightness. These were put horizontally adjacent to each other, and in the experiment the illuminance of one room was changed so that brightness of both rooms become the same or, in other words, so that the sizes of the RVSI of the two rooms become the same. They showed that the brightness of the two rooms approached the same level when the illuminance of the room of low lightness was increased considerably. Therefore they proved that the size of the RVSI is changed, depending upon the initial visual information.

We have studied a similar subject in which we have introduced a method ${ }^{45)}$ of measuring the apparent lightness of a test patch, that was put in a space in an effort to directly measure the size of the RVSI. This is because it is considered that the apparent lightness of the test patch is judged in light of the size of the RVSI of the room. In this experiment, the two miniature rooms consisting of compositional elements with high and low lightness were prepared and put horizontally adjacent to each other, in the manner similar to the experiment by Ikeda et al. The apparent lightnesses of the test patches in both spaces were compared and the difference was measured, while the horizontal illuminances of both rooms were set to be the same. The result was in compliance with what was assumed before the test, and the apparent lightness was higher when it was put in the room with low lightness. This indicates that the measurement of the apparent lightness of the test patches is effective for the study of the size of the RVSI.

Furthermore, we have implemented a similar experiment with these two rooms put one in front and one at the rear ${ }^{6}$. However, the apparent lightness of the test patches was measured by means of matching with a gray scale in the experiment. Then, we have shown, as anticipated that the 
test patch that was put in the front room, composed of walls and furniture with low lightness, indicated a higher apparent lightness when compared to the test patch put in the rear room with high lightness.

In the above experiment the two rooms were set in front and at the rear in order to make the influence of the simultaneous contrast between the test patch and back wall constant. This regardless of the room where the test patch is positioned. However, the boundary between the two rooms should be transparent because it is necessary for the subjects to see the inside of the rear room through the front room. However, the separation of the RVSI for each space would be difficult if there is no partition that physically separates the two rooms. Hence, a partition frame that projects from the four sides at the boundary of the two rooms with a certain width was set, this in the expectation that the RVSI of the two spaces, could be sufficiently segregated in this experiment. However, the experimental results indicated that the apparent lightness of the test patch changed gradually in the vicinity of the boundary of the two rooms, and that the size of the RVSI for one space gradually changed to that of another space.

One of the applications of the concept of the RVSI for the lighting design, is to create two RVSI out of single room by changing the interior applying the concept of area. In this case, the subject of study is the amount of separation of the two RVSI and, furthermore, how it can be manipulated. In this experiment a partition frame was installed, assuming that it would help the separation. If this were true, it could be expected that the separation would become clearer when the width of the partition frame is increased. The purpose of this study is to clarify this point. We will study how the apparent lightness of the test patch changes along the depth direction, this due to changes in the size of the projecting portion, and especially, if the apparent lightness is changed drastically at the boundary of the two rooms when the projecting portion gets larger. Conversely, if it changes more smoothly when the projecting portion gets smaller.

\section{Experiment}

\subsection{Experimental Apparatus}

In the experimental apparatus, as shown in Fig. 1, two miniature rooms were placed one in front and the other at the rear as seen from the position of the subject $\mathrm{S}$. The two rooms were separated by a partition frame $\mathrm{P}$. The front room as seen by the subject is called the front room $R_{f}$ and the rear room is called the back room $R_{b}$. The size of each miniature room was designed to be one tenth of an actual room, being $38 \mathrm{~cm}$ wide, $30 \mathrm{~cm}$ high, and $50 \mathrm{~cm}$ deep. Points $50 \mathrm{~cm}$ from the back wall of the back room constituted the boundary of the two rooms. The subjects observed the two rooms through an opening in the front room. The test patch $\mathrm{T}$, for assessment of lightness, was placed at the end

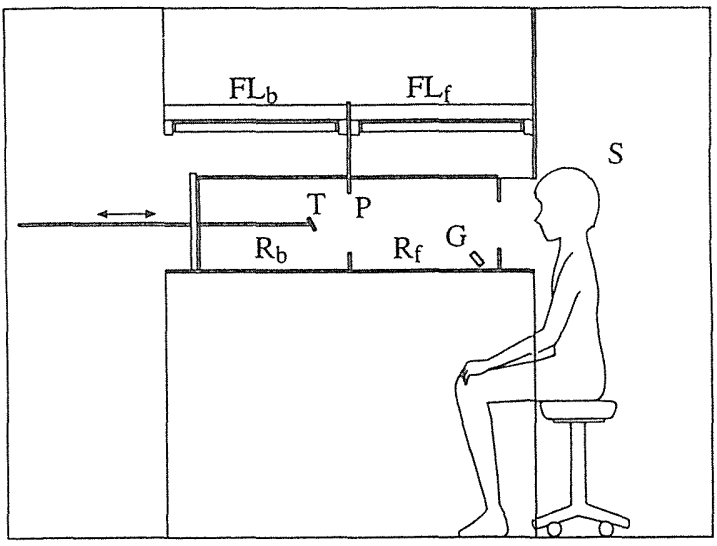

Fig. 1 Side view of apparatus. $R b$, back room; $R f$, front room; $P$, partition frame; FLb and FLf, fluorescent lamps of back and front room respectively, $T$, test patch; $G$, gray scale; $S$, subject

of a rod that extended from the back wall. It was slightly inclined upwardly so that it could reflect the illumination from above. The experimenter could place the test patch at an arbitrary position in the depth direction by moving the rod to and from, as shown by the arrows. The subjects were required to assess the lightness of the test patch using the gray scale $G$, which was put in the front room. A milky white acrylic plate was put on the ceiling of each room, behind which pairs of $20 \mathrm{~W}, 4500 \mathrm{~K}$, high color rendering $\mathrm{AA}$ white fluorescent lamps $\mathrm{FL}_{\mathrm{f}}$ and $\mathrm{FL}_{\mathrm{b}}$ were placed. The experimenter could set the illuminance of each room independently using a light controller for the fluorescent lamps. He/she could check the horizontal plane illuminance of each room by means of illuminance sensors installed at the center of the floor of each room. In preparation for the experiment, he/she set the illuminance of the two rooms to be the same by equalizing the levels of the illuminance meters for the two rooms by adjusting the light controllers. The horizontal illuminance at the center of the floor of each room was set at $600 \mathrm{~lx}$.

Fig. 2 is the view of the miniature rooms seen from the site of the subjects. The subjects observed the inside of the rooms through the opening shown by a thick line in the

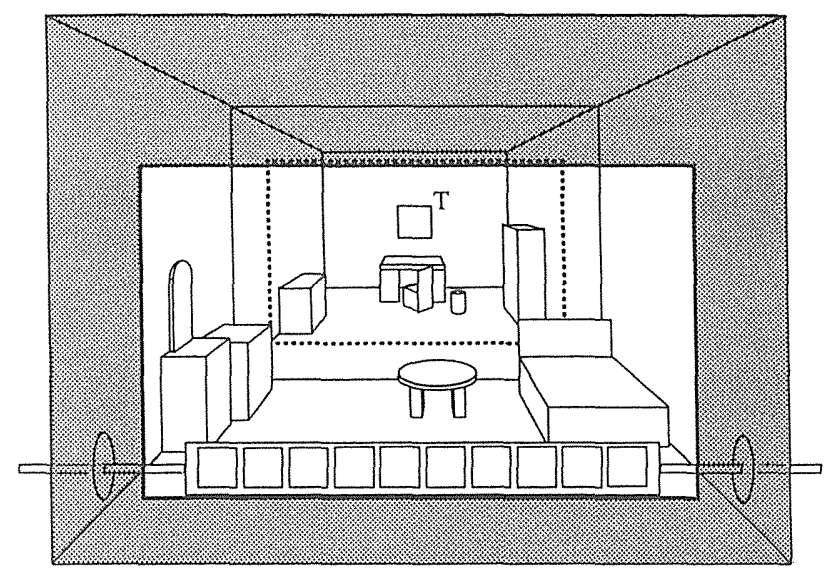

Fig. 2 View from the subject. $T$ indicates the test patch. 
Table 1 Lightness specification of the back and front rooms in Munsel Value.

\begin{tabular}{|c|l|l|l|}
\hline \multicolumn{2}{|c|}{ Back room } & Front room & \\
\hline Wall & N8.5 & Wall & $\mathrm{N} 7.0$ \\
\hline Floor & $\mathrm{N} 7.0$ & Floor & $\mathrm{N} 5.5$ \\
\hline Book shelf & $\mathrm{N} 7.0$ & Bed (upper plane) & $\mathrm{N} 5.5$ \\
\hline Chair & $\mathrm{N} 6.0$ & Bed (side plane) & $\mathrm{N} 4.5$ \\
\hline Desk & $\mathrm{N} 5.5$ & Dressing table & $\mathrm{N} 4.0$ \\
\hline Trash box & $\mathrm{N} 6.0$ & Table & $\mathrm{N} 4.5$ \\
\hline Chest & $\mathrm{N} 6.0$ & Chest & $\mathrm{N} 4.5$ \\
\hline
\end{tabular}

figure. The shadowed portion is the wall, but the subjects could see this portion of the room to some extent since they were permitted to move their heads freely. Although a partition frame as shown by a dotted line was projected at the boundary between the front and back rooms, the subjects could see through both rooms sufficiently because the opening in the partition frame was large. The width of this partition frame would be varied in the experiment. In Fig. 2, an opening of $20 \times 30 \mathrm{~cm}$ is shown. Miniatures of a bed, a dressing table, a table, and a chest were put in the front room and miniatures of a book shelf, a chair, a table, a trash box, and a chest were put in the back room. $\mathrm{T}$ indicates the test patch. Achromatic papers were pasted on all surfaces of the wall, floor, and furniture. Table 1 shows the lightness of each item in Munsell value. The interior of the front room was composed of the walls, floor, and furniture of which lightness was lower by 1.5 compared to the items in the back room. It was considered that the size of RVSI in the front room would be smaller than that of the back room with this arrangement.

The test patch was an achromatic paper of $5 \times 5 \mathrm{~cm}$ square. Since the test patch was put at the end of a rod that was extended from the back wall, it was seen by subjects as if it floated in the middle of the space. If the patch were directly put on the wall or furniture, it was feared that it would be affected not by the space but by the objects. In order to study the influence of the space, it was positioned in the midspace that could be seen to be independent from other objects. Although the rod supporting the patch was seen by the subjects when the patch got closer to the subjects, the fact that the patch was seen as independent from other objects remained unchanged. As mentioned before, the test patch was skewed upwardly by about $25^{\circ}$ so that it directly received the light from the ceiling. A mat color paper was used for the test patch in order to prevent the specular reflection of the light from fluorescent lamps and the reflected light from the walls.

The gray scale for assessing the lightness was attached on a bar that was horizontally across the front of the front room. Nineteen steps in total were shown. Or 10 scales from No.1 through No.10 in the front side, and another 10 scales from No.10 to No.19 in the back side. No.1 corresponded to $L^{*}=25$ and No.19 to $L^{*}=70$, and the row of scales increased by $2.5 L^{\star}$. The subjects could see both front and back plates by revolving the horizontal bar. Also the bar could be moved horizontally.

\subsection{Experimental Conditions}

The following three conditions were adopted for the different amounts of partition frame projection:

Condition $1.0 \mathrm{~cm}$ projection from the right and left walls and $0 \mathrm{~cm}$ from the floor and ceiling (the opening was $30 \mathrm{~cm}$ high $\times 38 \mathrm{~cm}$ wide)

Condition $2.4 \mathrm{~cm}$ projection from the right and left walls and $5 \mathrm{~cm}$ from the floor and ceiling (the opening was $20 \mathrm{~cm}$ high $\times 30 \mathrm{~cm}$ wide)

Condition $3.9 \mathrm{~cm}$ projection from the right and left walls and $10 \mathrm{~cm}$ from the floor and ceiling (the opening was $10 \mathrm{~cm}$ high $\times 20 \mathrm{~cm}$ wide)

Condition 2 is the same as had been applied in the previously reported study ${ }^{6}$. Condition 1 is the state in which there is no partition frame between the front and back rooms. Although condition 3 is the case with the greatest projection of the partition frame, the furniture and wall in the back room could be seen sufficiently by the subjects. In other words, the initial visual information for the back room was sufficiently provided.

The lightness of the test patch was set at two levels, N4 and N6. Measurement of the lightness of each test patch with a spectrophotometer gave $L^{*}=41.9$ and 61.5 , respectively.

The illuminance at the center of each room was set at 600 $\mathrm{lx}$. However, the illuminance in the rooms varied slightly by location, due to the influence of the length of the fluorescent lamps and the partition frame. Therefore, the luminance of the test patch surface also varied by its position in the depth direction. Fig. 3 shows the luminance at various position measured from the location of the subjects. The variation was small in condition 1 (without the partition frame) while it was large in condition 3 , with the large projection. However, the difference between the conditions was observed in the back room only. It is considered to have been caused by the light from the front room being intercepted by the partition frames. The influence

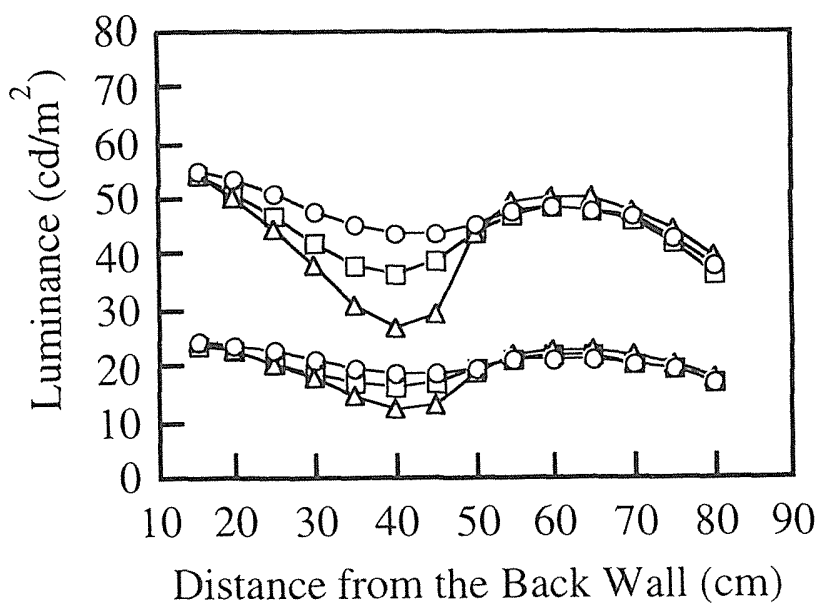

Fig. 3 Luminance of the test patch N6(upper) and N4 (lower) at various positions in depth. $O$, condition $1 ; \square$,condition2; $\Delta$, condition3. 
of the luminance variations of the test patch on the apparent lightness was excluded in the analysis of data. The adjustment method will be described in the section on the experimental results.

The subjects assessed the lightness of the patch, which was placed at a certain position in the depth direction, using the gray scale of 19 levels that was put in the front room. The number of positions for the patch was seven: $20,30,40$, $50,60,70$, and $80 \mathrm{~cm}$ from the back wall. The position at $50 \mathrm{~cm}$ was the boundary between the two rooms. One experimental block was composed of 14 combinations of two kinds of test patches and seven positions. One session was composed of two or three blocks, and the assessment was made on combinations that were presented at random. Eventually, each subject did assessments on ten blocks for each condition.

The subjects were instructed as follows: "Please adjust the height of the chair so that the ceiling can not be seen. Next is the assessment. Please select a piece of the gray scale that is seen to have the same lightness as the test patch, then let me know its number. You may interpolate or extrapolate the number, if necessary. Please avoid seeing specific objects in the rooms and please observe the whole space while making assessment. You may move your head freely. There is no limit to the observation time."

In the above instructions, the subjects needed to be unable to see the ceiling in order to exclude the ceiling light from the initial visual information. If they saw the ceiling, it would be obvious that the two rooms were equally illuminated. Regarding the movement of the head, movement of the head would be meaningless if the stimuli shown to the subjects were pictures on a CRT, for example. However, since miniature rooms in three-dimensional space were used in this experiment, we did not want to restrict the way of seeing and wanted to have the subjects see objects in a normal fashion. Also we gave them an unrestricted observation time since we wanted them to maintain their regular behavior patterns.

Exactly the same experimental steps were applied to conditions 1 through 3 . However, there were positions under condition 3 where the luminance of the test patch was extremely low, as shown in Fig. 3, where the apparent lightness was considerably lowered. Therefore, $L^{*}=22.5$ was added to the gray scale only for the experiment under this condition, and the scale No. 0 was attached to it.

The subjects were MII (age 64, male), HS (age 31, male), YM (age 23, female), RY (age 22, female) and YH (age 21, female), five persons in total. Each person had normal color perception. This was the first experience for $\mathrm{RY}$ and $\mathrm{YH}$ of participating in such a psychophysical experiment.

\section{Results and Discussion}

The results of subject YM for condition 1 (the case of no partition frame), condition 2 (the case of a narrow partition frame), and condition 3 (the case of a wide partition frame) are shown in Fig. 4. By the way, the results for condition 2 were taken from the already-reported study ${ }^{6}$ ) that are shown in order to compare the results of the three conditions. The upper and lower data are for test patches N6 and N4, respectively. The abscissa indicates the distance from the back wall and the position at $50 \mathrm{~cm}$ is the boundary of the two rooms. The ordinate shows the levels of assessment based upon the gray scale as they were reported in units of $L_{\mathrm{raw}}{ }^{*}$. Black circles on the vertical axis indicate the $L^{*}$ value of the test patch $\mathrm{N} 4$ (lower position) and N6 (higher position). Although the number of data points is ten for each position of the test patch, a smaller number of points are shown due to overlapping. Solid curves show the averages. As it is clearly seen in the figure, the lightness of the test patch was obviously assessed to be higher when it was positioned in the front room compared to when it was positioned in the back room. However, since the actual luminance of the test patch varies depending upon its position as mentioned in Fig. 3, it is necessary to apply an adjustment to the results in Fig. 4. Following is an explanation of the method of adjustment.

The lightness of the test patch $L_{\text {raw }}{ }^{*}$ is that assessed on the test patch of which the luminance was $Y_{\text {raw }}$ as given by Fig. 3. Therefore, the following equation is valid:

$L_{\text {raw }}{ }^{*}=116\left(Y_{\text {raw }} / Y_{0}\right)^{1 / 3}-16$

Here, $Y_{0}$ is the $Y$ value of a perfect reflecting diffuser. Then, the apparent lightness of the test patch $L_{\mathrm{aa}}{ }^{*}$, assuming the case that the luminance of the test patch $Y_{\text {raw }}$ was changed to a certain luminance $Y$, is given by the following equation:

$L_{\text {ap }}{ }^{*}=116\left(Y / Y_{0}\right)^{1 / 3}-16$

Here, $m=Y / Y_{\text {raw }}$ is inserted to obtain,

$$
\begin{aligned}
L_{\text {ap }}{ }^{*} & =116\left(m Y_{\text {raw }} / Y_{0}\right)^{1 / 3}-16 \\
& =m^{1 / 3}\left\{L_{\text {raw }}{ }^{*}+16\left(1-1 / m^{1 / 3}\right)\right\}
\end{aligned}
$$

In other words, $L_{\text {ap }}{ }^{*}$ is given by $L_{\text {raw }}{ }^{*}$ and $m$. The apparent lightness in the case of uniform luminance of the test patch $Y$ that was obtained after the adjustment described above was adopted as the result. Then the average of the luminance measurement at each position of the test patch in condition 2 was adopted, as the $Y$ value to obtain $19.5 \mathrm{~cd} / \mathrm{m}^{2}$ for the test patch $\mathrm{N} 4$ and $44.1 \mathrm{~cd} / \mathrm{m}^{2}$ for N6. These $Y$ values were used also to adjust the results of condition 1 and condition 3 .

The values of $L_{\mathrm{ap}}$ * that were obtained through the application of this adjustment on Fig. 4 are shown in Fig. 5. The ordinate is the apparent lightness after the adjustment $L_{a p}{ }^{*}$. Although the variations in the apparent lightness became loose compared to Fig. 4, there was no change in the results that the apparent lightness in the front room is higher than that in the back room. 
(a)

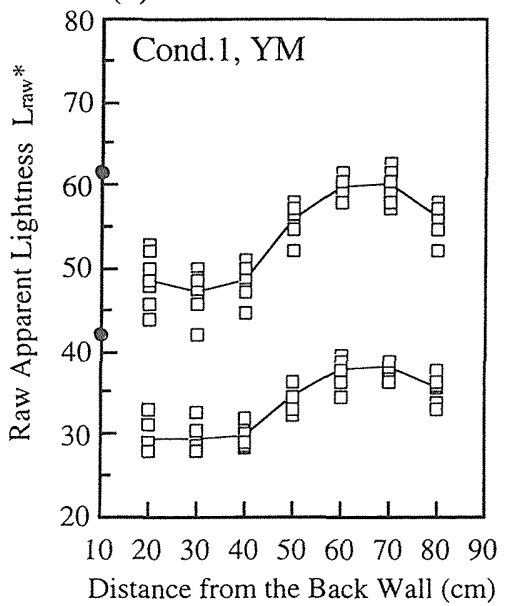

(b)

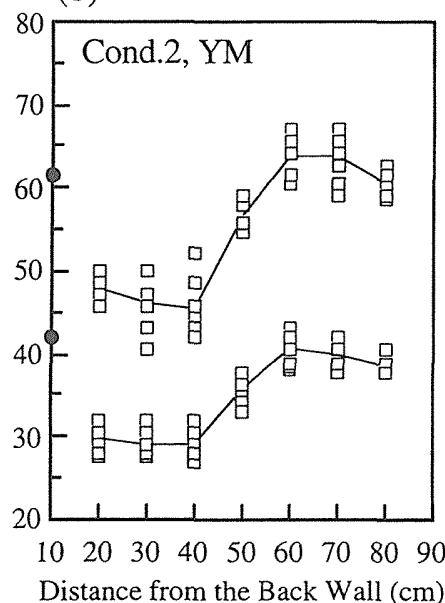

(c)

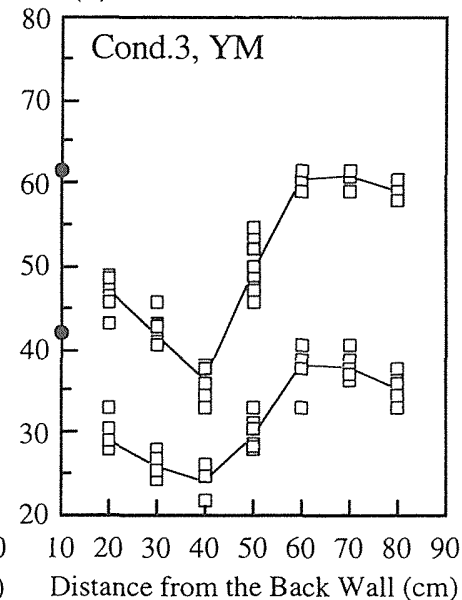

Fig. 4 Raw data of apparent lightness assessed by subject YM for N6 (upper) and N4 (lower) plotted against the distance from the back wall. Solid curves are the average. Each figure corresponds to conditions of partition frame.

(a)

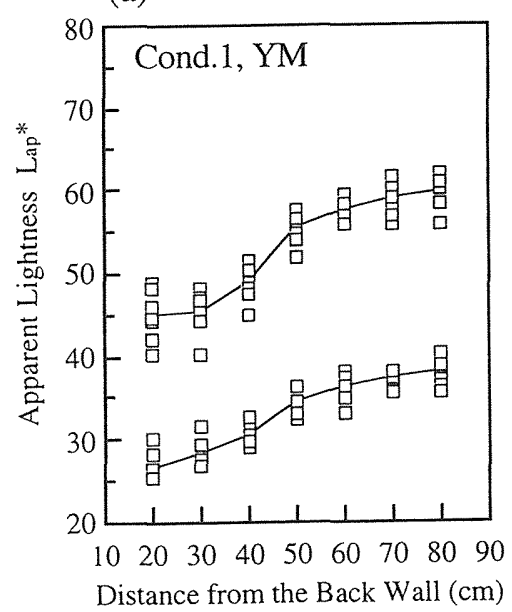

(b)

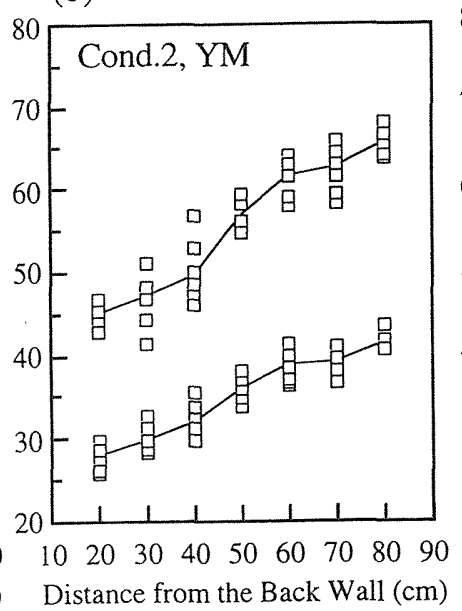

(c)

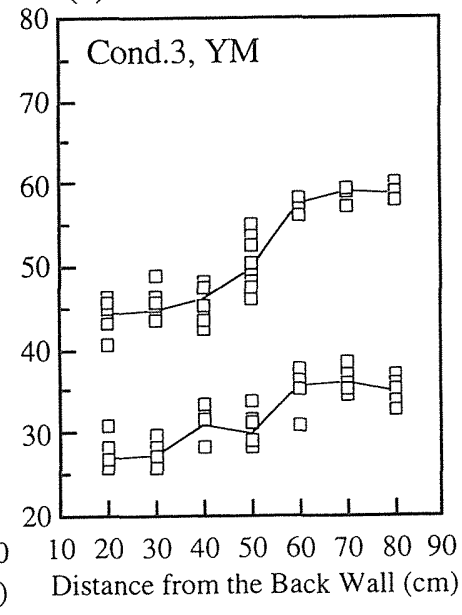

Fig. 5 Apparent lightness at various positions of the test patches corrected for the patch luminance. Upper group, test patch of N6; lower, N4. Subject, YM. Solid curves are the average.
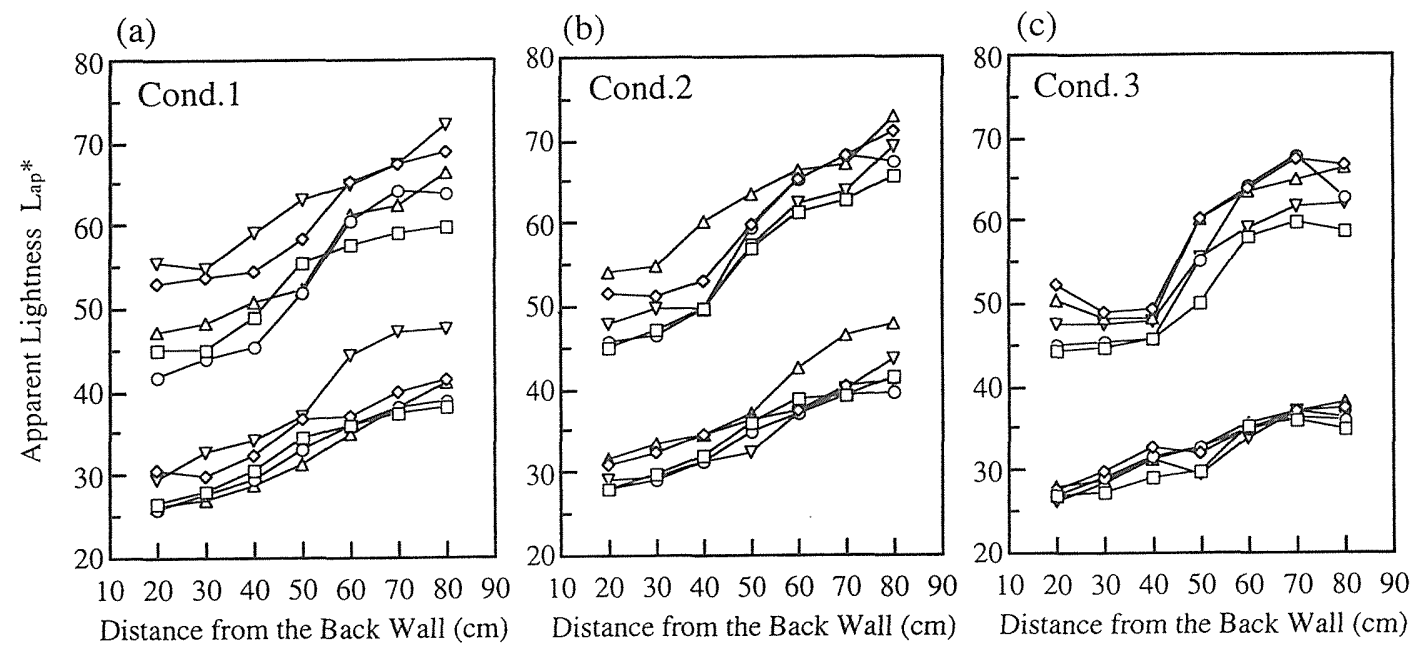

Fig. 6 Apparent lightness at various positions of test patch. Different symbols correspond to subjects; $O, M i ; \diamond, H S ; \square, Y M ; \nabla, R Y ; \Delta, Y H$. Upper group, test patch of N6; lower, N4. 
The results for all subjects are summarized and shown in Fig. 6. Symbols indicates the different subjects. The ordinate is $L_{\text {ap }}{ }^{*}$ after adjustment. Each subject shows the same tendency, and the apparent lightness of the test patch is apparently high when the patch is in the front room. This indicates that, while the size of the RVSI in the front room is smaller when compared to that in the back room (despite both rooms having the same illuminance). The apparent lightness of the patch is low in the back room with a large size, but is high in the front room with a small size, since the appearance of the test patch is determined by the size of each RVSI.

Fig. 6 also shows deviations between subjects. However, the shapes of the curves that get higher toward the right side resemble each other well, and the deviations are observed mainly in the vertical direction of the curves. It can be assured that the deviations get smaller when the conditions shift in the sequence of 1,2 , and 3 . This shows that a stable size of the RVSI is formed when the projection of the partition frame is enlarged. On the contrary, it seems to be appropriate to say that, when two RVSIs are created by the interior arrangement alone without a partition, their sizes are unstable and vary depending upon personal judgement.

Fig. 7 shows the averages of all the subjects by condition. Symbols indicate the different conditions. No conspicuous differences in the shapes of the curves by condition are noted. We would like to pay special attention to the point that no obvious differences by condition in the slopes of the changes in the apparent lightnesses in the vicinity of the partition frame were observed. Although it was initially assumed that the change in sizes of the RVSI for the two rooms would be drastic and that the separation would become obvious by enlargement of the partition frame, there seems to be no such effect. When this is considered from the view of practical application, it means that a special partition frame is not required but that the interior alone should be modified in order to produce two psychologically recognizable spaces out of one space.

In order to see the differences of $L_{\mathrm{ap}}{ }^{*}$ in the front and back rooms, the average of $L_{\mathrm{ap}}{ }^{*}$ for the cases of the test patch positioned at $20 \mathrm{~cm}$ and $30 \mathrm{~cm}$ from the back wall, the same at $70 \mathrm{~cm}$ and $80 \mathrm{~cm}$, and their difference are shown in Table 2. Since there was no large difference in each average due to differences in conditions, averages of all the conditions are calculated and shown in the bottom section.

Fig. 8 (a) was developed to see the relationship between $L^{*}$ and $L_{\mathrm{ap}}{ }^{*}$. When $L^{*}=0, L_{\mathrm{ap}}{ }^{*}$ is also assumed to be 0 . The narrow solid line indicates the case of $L^{*}=L_{\mathrm{ap}}{ }^{*}$. $L_{\mathrm{ap}}{ }^{*}$ for the front room is nearly on this line. It is considered to be reasonable since the gray scale for matching was placed in the front room. Fig. 8 (b) shows the difference of $L_{a p}{ }^{*}$ in the front and back rooms which was plotted as a function of $L^{*}$ of the test patch, and this suggests that both of them have a linear relationship.

As described in the introduction, the rooms were positioned in the front and the rear from the viewpoint of

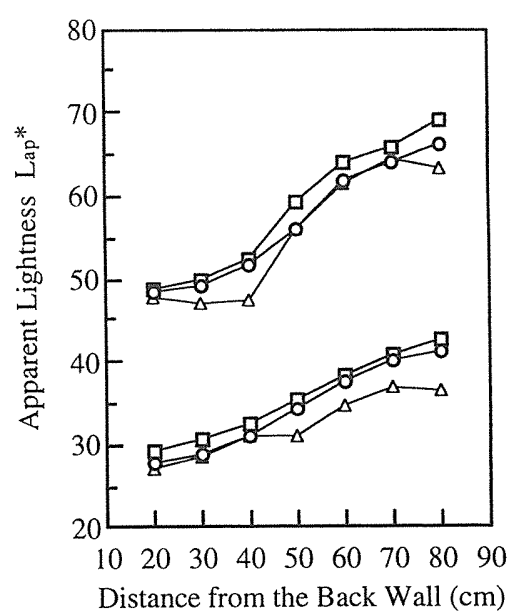

Fig. 7 Apparent lightness at various positions of test patch. Average of five subjects for different conditions; $O$, condition1; $\square$,condition2; $\Delta$, condition3. Upper group, test patch of N6; lower, N4.

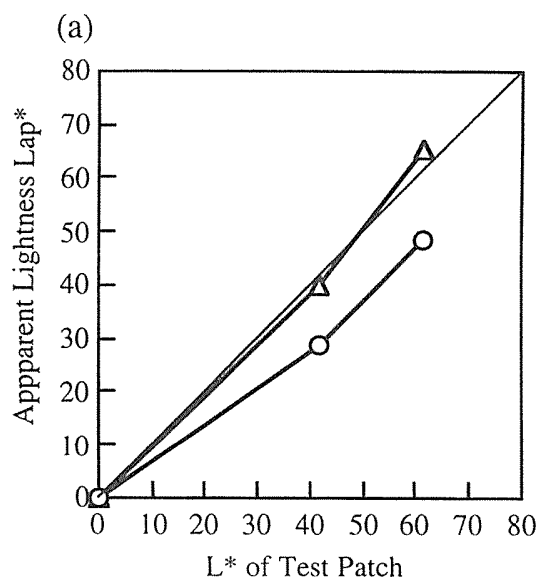

(b)

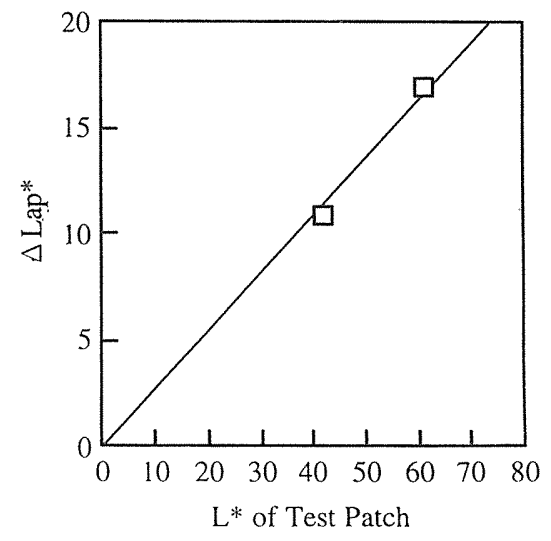

Fig8 (a) Relationship of the apparent lightness Lap* to the lightness of the test patch $L * ; \Delta$, front room; $O$, back room. (b) Relationship of the difference of the apparent lightness $\Delta$ Lap* between front and back room to the lightness of the test patch $L *$. 
Table.2 Apparent lightness Lap* for each room and the difference between front and back room $\triangle$ Lap*.

\begin{tabular}{|c|c|c|r|r|r|}
\hline Condition & $\begin{array}{c}\text { Munsell } \\
\text { Value }\end{array}$ & $L^{*}$ & $\begin{array}{c}L_{\text {app }}{ }^{*} \\
\text { (back) }\end{array}$ & $\begin{array}{c}L_{\text {ap }}{ }^{*} \\
\text { (front) }\end{array}$ & \multicolumn{1}{|c|}{$\Delta L_{\text {ap }}{ }^{*}$} \\
\hline \multirow{2}{*}{1} & $\mathrm{~N} 4$ & 41.9 & 28.3 & 40.6 & 12.3 \\
\cline { 2 - 6 } & $\mathrm{N} 6$ & 61.5 & 48.7 & 65.1 & 16.4 \\
\hline \multirow{2}{*}{2} & $\mathrm{~N} 4$ & 41.9 & 30.0 & 41.8 & 11.8 \\
\cline { 2 - 6 } & $\mathrm{N} 6$ & 61.5 & 49.2 & 67.5 & 18.3 \\
\hline \multirow{2}{*}{3} & $\mathrm{~N} 4$ & 41.9 & 27.8 & 36.5 & 8.7 \\
\cline { 2 - 6 } & $\mathrm{N} 6$ & 61.5 & 47.3 & 63.7 & 16.4 \\
\hline \multirow{2}{*}{ Mean } & $\mathrm{N} 4$ & 41.9 & 28.7 & 39.6 & 10.9 \\
\cline { 2 - 6 } & $\mathrm{N} 6$ & 61.5 & 48.4 & 65.4 & 17.0 \\
\hline
\end{tabular}

the subjects so that the luminance contrast between the test patch and the background, despite the position of the patch, remain unchanged on the retina. Therefore, simultaneous contrast, lateral inhibition, and so on between the test patch and the back wall remained unchanged, and, accordingly, the cause of the changes in the apparent lightness of the test patch cannot be due to the effects at the retinal level. The apparent lightness was determined based upon the recognition at the brain level or in which room the test patch was placed. However, the size of the test patch on the retina gets larger when the test patch gets closer to the subject. It may be possible to suggest that the changes in the size should affect the apparent lightness. However, there is no phenomenon in our daily life in which the lightness of a object is seen as being changed when a object is coming toward us, or when we are going towards a object. Therefore, it is considered that such a suggestion is invalid. In order to ensure it, the lightness assessment was implemented in the condition that the size of the test patch was kept constant on the retina by changing its size by position. As we assumed, there was no change in the apparent lightness compared to the basic experiments in this study. It can be concluded that the size of the test patch on the retina has no influence on the apparent lightness. It is considered appropriate to explain the experimental results of this study by the size of the recognized visual space of illumination, RVSI, as described before.

A part of this study was carried out using the Sixth Supporting Fund of the Institute of Illuminating Engineering, Japan for Study and Education. We would like to express our thanks.

\section{References}

(1) Ikeda, Motonaga, Matsuzawa, and Ishida: "Threshold Determination for Unnatural Color Appearance with Local Illumination", Optics, 22-5, pp.289-298 (1993)

(2) Ikeda, Yoon, and Shinoda: "Continuity between Two Recognized Visual Space of Illumination", Journal of IEIJ, 79-11, pp.710-713 (1995)

(3) Ikeda, and Kaneko: " Effect of Initial Visual Information on the Recognized Visual Space of Illumination - The Case of Lightness and Saturation", Journal of IEIJ, 80-5, pp.319-324 (1996)

(4) Mizokami, Ikeda, Shinoda: "Lightness Judgment in Relation to the Size of the Recognized Visual Space of Illumination Controlled by Lightness and Color Saturation of Objects", Proc. 8th Congress of Int. Colour Assoc. I , pp.167-170 (1997).

(5) Mizokami, Ikeda, and Shinoda: "Apparent Lightness Influenced by the Size of the Recognized Visual Space of Illumination", Journal of IEIJ, 82-2, pp.91-96 (1998)

(6) Mizokami, Ikeda, Shinoda: "Lightness Change as Perceived in Relation to the Size of Recognized Visual Space of Illumination", Optical Review, 5-5, pp.315319 (1998) 